\title{
Deglutition and Cough in Different Degrees of Parkinson Disease
}

\author{
Deglutição e Tosse nos Diferentes Graus da Doença de Parkinson
}

\author{
Aretuza Zaupa Gasparim*, Ari Leon Jurkiewicz**, Jair Mendes Marques ***, \\ Rosane Sampaio Santos $* * * *$, Paulo Cesar Otero Marcelino $* * * *$, Francisco Herrero Junior $* * * * *$.
}

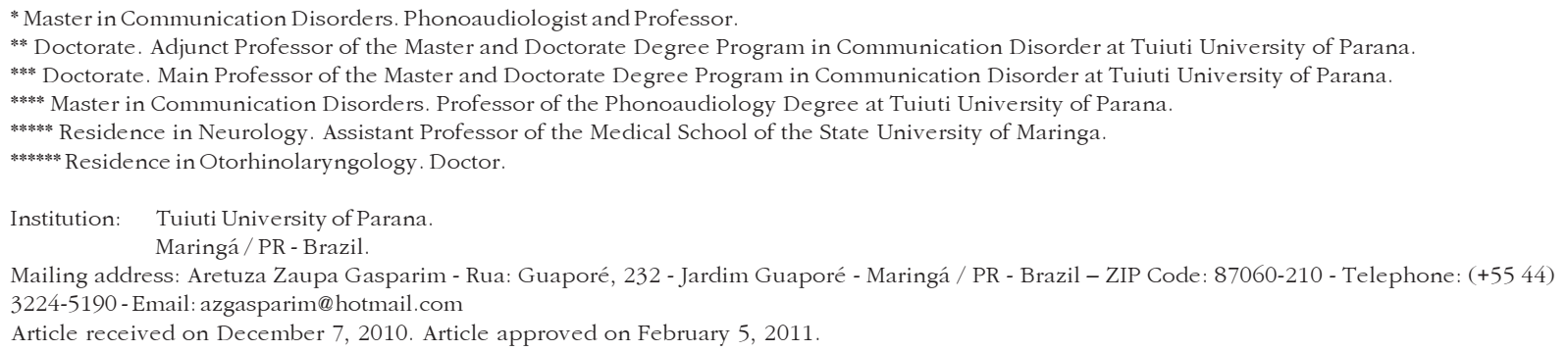

\section{SUMMARY}

Introduction:

Objective:

Method:

Results:

Conclusion:

Keywords:

\section{RESUMO}

Introdução:

Objetivo:

Forma de estudo: Método:

Resultados:

Conclusão:

Palavras-chave:
Parkinson disease is one of the pathologies mostly affecting deglutition.

To analyze the efficiency of both deglutition and cough reflex in cases of laryngeal penetration or tracheal aspiration with food, in different severity stages of Parkinson disease. Study's way: contemporaneous cohort with transverse incision.

The sample had 38 patients in the study group and 38 individuals in the control group submitted to a neurologic evaluation and an otorhinolaryngological evaluation by transnasal fiberoptic laryngoscopy. The cough reflex was manifested in 100\% of patients without food offering. Alimentary stasis in piriform recesses and epiglottic vallecula in solid, pasty and liquid consistency was significant $(p=0.0000)$. The laryngeal penetration in liquid consistency was significant $(p=0.0036)$. Tracheal aspiration occurred in 06 patients of the study group in liquid consistency and it was absent in control group.

The efficiency of deglutition in the study group prevailed in the solid consistency, followed by pasty and liquid consistencies. In the control group, deglutition was effective in all individuals. Cough reflex was efficient in most patients of the study group and prevalently inefficient in the subgroup 2. Parkinson disease, cough, deglutition disorders.

A doença de Parkinson é uma das patologias que mais comumente afetam a deglutição. Analisar a eficácia da deglutição e do reflexo de tosse nos casos de penetração laríngea ou aspiração traqueal com alimento, em diferentes estágios de severidade na doença de Parkinson. Corte contemporânea com corte transversal.

A amostra constou de 38 pacientes no grupo de estudo e 38 indivíduos no grupo-controle submetidos a uma avaliação neurológica e uma avaliação otorrinolaringológica pela nasofibrolaringoscopia. O reflexo de tosse manifestou-se em 100\% dos pacientes sem a oferta de alimento. A presença de estase alimentar em recessos piriformes e valéculas epiglóticas na deglutição das consistências líquida, pastosa e sólida foi significativa $(\mathrm{p}=0,0000)$. A ocorrência de penetração laríngea na consistência líquida foi significativa $(\mathrm{p}=0,0036)$. Aspiração traqueal ocorreu em seis pacientes do grupo de estudo na consistência líquida, e ausente no grupo-controle.

Eficácia da deglutição no grupo de estudo predominou na consistência sólida, seguida da consistência pastosa e líquida. No grupo-controle a deglutição foi eficaz em todos os indivíduos. O reflexo de tosse foi eficaz na maioria dos pacientes do grupo de estudo e a sua ineficácia predominou no subgrupo 2.

doença de Parkinson, tosse, transtornos de deglutição. 


\section{IINTRODUCTION}

Parkinson's disease (PD) is comprised of a number of neural systems and it is caused by changes in a few and vulnerable kinds of nervous cells. It is a degenerating and progressive disease of the central nervous system and it starts in the dorsal motor nuclei of the glossopharyngeal and vagal nerves as well as in the anterior olfactory nucleus (1).

Next, the disease is manifested by the reduction in the production of dopamine, which is an important neurotransmitter in the control of movements, as a result of the neuronal degeneration into the compact part of the black matter. Main signs of the disease are: Trembling during relaxation, bradykinesia, muscle rigidity and postural alteration $(2,5,4)$.

Clinically, in addition to the classic tetrad of PD, other manifestations can be observed during its development: loss of facial expression, micrograph, autonomic alterations - dysphagia, salivation, gastric emptying disorder, urinary retention, sexual dysfunction, sleep alteration and sensorial disorders $(2,4)$.

Dysphagia is frequent during PD development and it is not always associated with the severity of the latter.

The difficulty in the process to swallow food in PD is caused by the inability to rapidly and coordinately perform the movements involved in this process (4). As a result of the muscular rigidity and bradykinesia, dysphagic manifestations can come from the delay in both the deglutition reflex and the reduced mobility of oropharyngeal structures, with a possibility of premature loss of food and its accumulation in the oral part of the larynx, epiglottic vallecula (EV) and piriform recesses (PR), what enables pulmonary aspiration (6).

The episodes of laryngotracheopulmonary aspiration are often manifested when the protective mechanisms of the airways are inefficient. The deterioration of the control of pharyngeal, laryngeal and respiratory muscles as well as that of the protective reflexes, such as cough, allows for the high incidence of aspiration pneumonia in PD (7).

The function of cough reflex (CR) is to remove secretion and/or a strange body from the airways, causing an important expiratory flux in the defense against pneumonia by aspiration $(8,9)$. The parkinsonian symptoms and PD evolution are relevant to the inefficiency of the oropharyngeal mechanisms of deglutition, breathing, phonation and protective reflexes of the lower airways.
Researches show alterations in DP deglutition through findings of silent aspirations and a reduction in the laryngeal sensitivity, but in a few studies they analyzed TR in PD $(7,8)$, and there is no investigation of dysphagia and TR in DP by transnasal fiberoptic laryngoscopy.

The objective is to analyze the efficiency of both deglutition and cough reflex in cases of laryngeal penetration (LP) or tracheal aspiration (TA) with food, in different severity stages of Parkinson disease.

\section{MetHOD}

38 individuals with PD (study group) and 38 individuals without a neurological disease (control group) have been studies, out of whom 22 were male (57.9\%) and 16 were female (42.1\%) for each studied group, in the age group between 40 and 86 . The age average of the study group is 69.4 years and the standard deviation is of 11.8 years; in the control group the age average was 65.7 years and the standard deviation was 14.9 years.

The individuals signed a Free Agreement and Clarified Term approved by the Ethical Committee (№ 101/2007) and they were informed about the objectives of the research, procedures to be taken and the guarantees of the study.

The inclusion criteria for the study group were to be in the stages 1 to 4 of the modified HoEHN \& YAHR (1976)'s Staging Scale (10) - (Annex 1), with a swallowing complaint and no other correlated neurological disease. The stage 5 of this disease includes patients greatly weakened by PD, what would make it difficult to use the study protocol, as well as the possibility of aspirating complications, and, therefore, it is included as an exclusion criterion. The control group showed neither neurological diseases nor swallowing disorders.

Each individual was submitted to a phonoaudiological anamnesis to collect data with respect to swallowing complaints and dysphagia symptoms. They were additionally submitted to a neurological clinic and an otorhinolaryngologic evaluation (transnasal fiberoptic laryngoscopy) in the on PD status and not longer than 4 hours after drugs have been ingested.

The study group was divided into four subgroups: subgroup 1 (stages 1 e 1,5), 7 patients (18,4\%); subgroup 2 (stages 2 e 2,5), 19 patients (50\%); subgroup 3 (stage 3), 8 patients (21\%) e subgroup 4 (stage 4 ), 4 patients $(10,5 \%)$. 
Annex I. Scale of Hoehn \& Yahr staging (1967), modified $^{10}$.

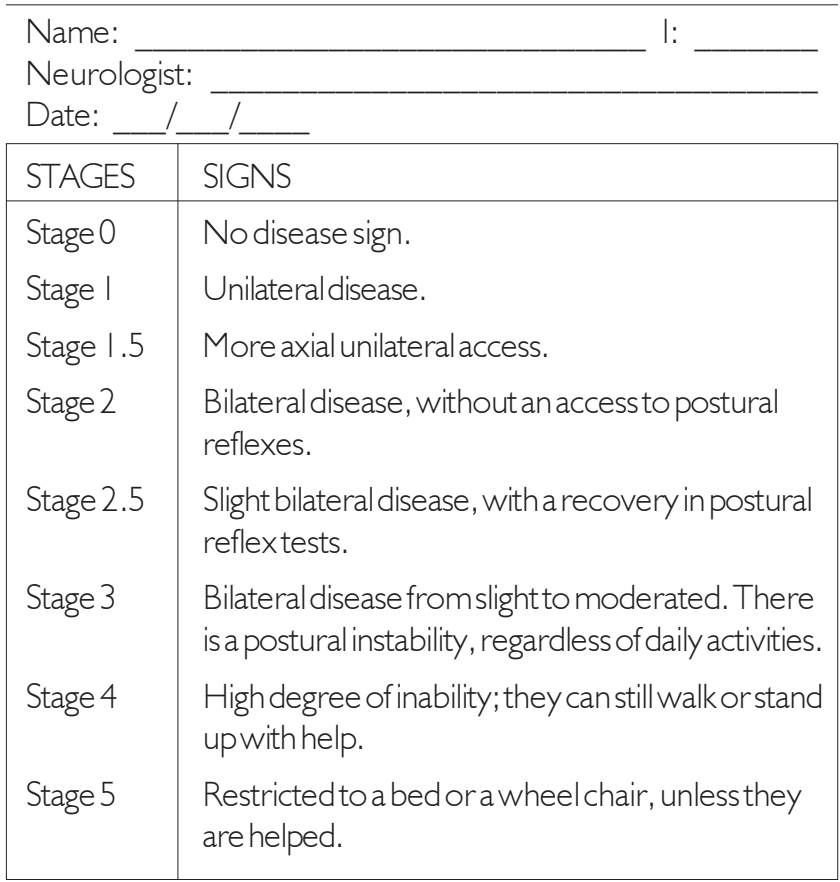

To perform transnasal fiberoptic laryngoscopy, the following equipment was used: Flexible optic fiber (Mashida - ENT 30PIVE), endoscopic camera (WatecWAT2315), light source (Factory - $250 \mathrm{~W}$ ), adapted to video system, what allowed the examinations to be recorded. The video system was comprised of: TV (Panasonic - 435) and videocassette recorder (HPS 1407). The examinations were recorded in a videotape (Sony - ED T-160 model).

When the patient is sitting without using any topic anesthetic drug, fiber optic scope is targeted at the nasal cavity, oral and laryngeal parts of the larynx and pharynx to observe morphology - appearance, symmetry and structural lesions of these anatomic areas in relaxation state. CR was researched by the touch of the fiber optic scope on the lingual basis (LB), laryngeal face of epiglottis (LFE), vestibular and aryepiglottic folds without food, and taking into consideration the dynamic evaluation of deglutition, the pharyngeal stage was analyzed by using food in liquid, pasty and solid consistencies colored with methylene blue to enhance visualization. Each consistency was offered twice in a two-minute interval, with the following volumes: liquid (water) $5 \mathrm{ml}$, pasty (Alimentary thickening was used by adding amide to water, in accordance with the standardization of the consistencies of Thick \& easy product $\left.{ }^{\circledR}\right) 5 \mathrm{ml}$ and solid (one-third of wafer cookie).

In all the Alimentary consistencies, the individual was guided to maintain the food in their mouth for a few seconds until he/she is authorized to swallow, in order to observe the premature escape from the pharynx and larynxarea.

The swallowing efficiency was regarded as effective in the liquid, pasty and solid consistencies when LP or TA were absent. In ineffective deglutition, stasis was manifested in the area of the posterior wall of pharynx (PWP), LB, LFE, $\mathrm{EV}$ and PR, as well as CR efficiency.

In the Alimentary consistencies, after food was introduced, in cases of laryngeal penetration or tracheal aspiration, cough reflex was considered effective in the manifestation of clean cough and the protection of the laryngotracheal area, and it was not effective when cough was absent.

The otorhinolaryngologic evaluation was recorded in a standard questionnaire prepared by the researcher of this study (Annex 2).

The evaluations in the modified HoEHN \& YAHR (1976)'s Staging Scale (10) and the otorhinolaryngologic evaluations were compared with each other, for each individual. Descriptive methods (tabular and graphic) and statistical tests of Proportion Differences and Fisher at a significant level were performed.

\section{RESULTS}

Dysphagia symptoms were analyzed: lack of air during nutrition, phlegm, nasal regurgitation and sensation of food stuck in throat (SFST), in both groups, and a significant result $(\mathrm{p}=0.0002)$ was achieved only in SFST symptom. When food was not present, TR was found in all the patients of both groups.

In the study group, laryngeal sensitivity appeared to be reduced in the subgroup 1 in two patients, in the subgroup 3 in 4 patients, and in the control group in two cases of minor statistical relevance.

Swallowing liquid food was effective in 13 individuals (34.2\%) of the study group and in 32 individuals (84.2\%) of the control group, and the highest incidence of stasis was in the area of $P R$ with a significant statistical value $(\mathrm{p}=0.0000$, Table 1).

Swallowing pasty food was effective in 7 individuals (18.4\%) of the study group and in 26 individuals (68.4\%) of the control group, and the highest incidence of stasis was in the area of $P R$ with a significant statistical value $(p=0.0000$, Table 2).

In the deglutition evaluation for solid consistency, 17 patients (44.7\%) of the study group and 29 individuals 
Annex 2. Otorhinolaryngological evaluation.

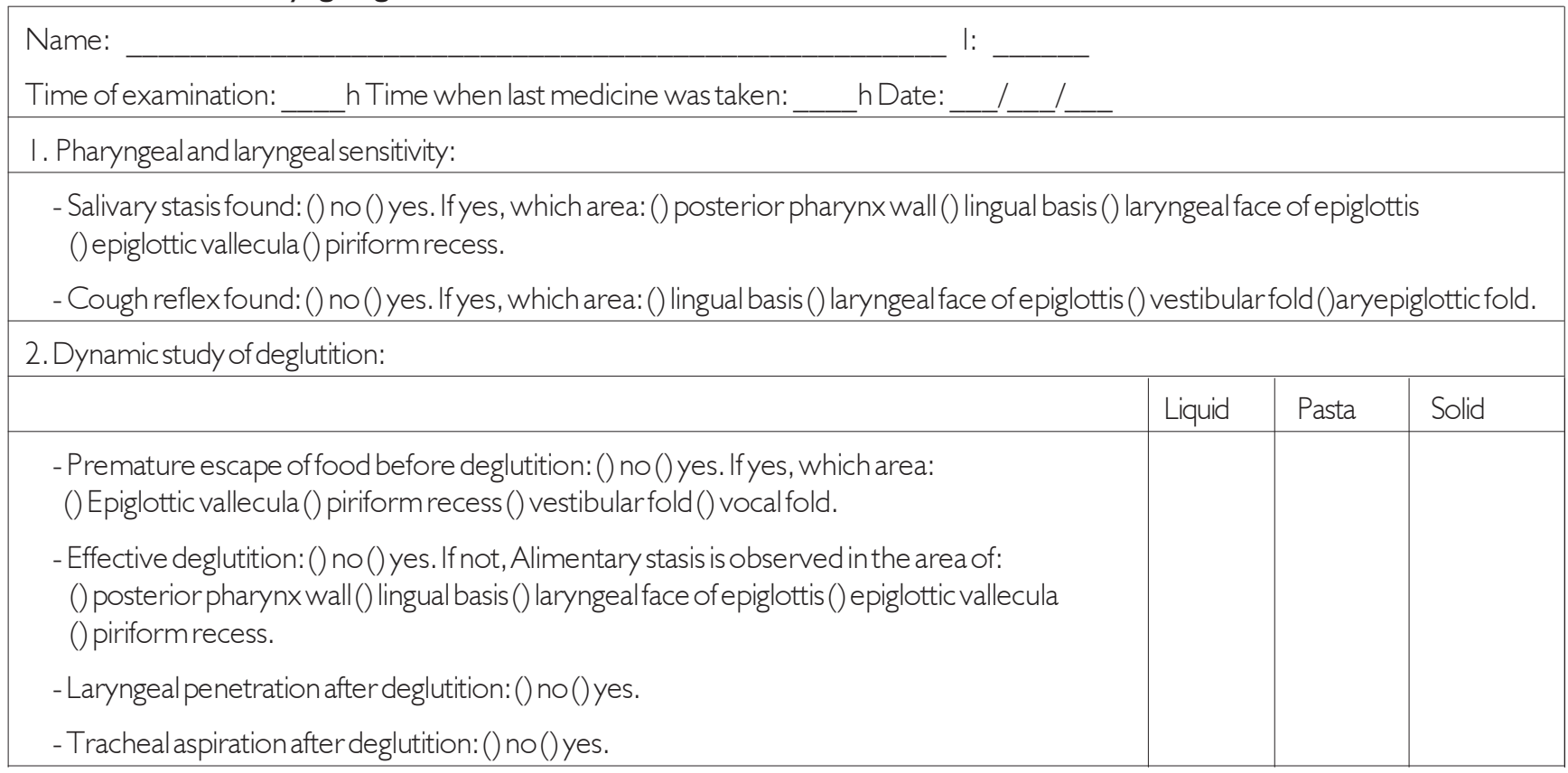

Table I. Alimentary stasis found in liquid consistency.

\begin{tabular}{|c|c|c|c|c|c|c|}
\hline \multirow[t]{2}{*}{ Anatomic location } & \multicolumn{2}{|c|}{ Studygroup } & \multicolumn{2}{|c|}{ Controlgroup } & \multirow{2}{*}{\multicolumn{2}{|c|}{ Total }} \\
\hline & SI & $\mathrm{S} 2$ & S3 & S4 & & \\
\hline PWP & - & I & - & - & - & 1 \\
\hline PR & - & 3 & । & । & 3 & 8 \\
\hline EV & - & - & । & - & 2 & 3 \\
\hline$L B+P R$ & - & | & - & - & - & | \\
\hline$L B+E V$ & - & - & । & - & - & | \\
\hline$P R+E V$ & । & 2 & 2 & । & । & 7 \\
\hline $\mathrm{BL}+\mathrm{PR}+\mathrm{EV}$ & - & l & । & - & - & 2 \\
\hline$L F E+E V+P R$ & - & 1 & - & - & - & | \\
\hline$L B+L F E+E V+P R$ & - & 3 & - & - & - & 3 \\
\hline$L B+L F E+P W P+E V+P R$ & - & I & 2 & । & - & 4 \\
\hline Total & 1 & 13 & 8 & 3 & 6 & 31 \\
\hline
\end{tabular}

Legend: LB: Lingual basis; LFE: Laryngeal face of the epiglottis; PWP: Posterior wall of the pharynx: PR Piriform recess; EV: Epiglottic vallecula; S1 (stages 1 and 1.5); S2 (stages 2 and 2.5); S3 (stage 3); S4 (stage 4).

Test of proportion differences: $\mathrm{p}=0,0000$.

(76.3\%) of the control group did not have stasis. The highest occurrence of stasis was observed $n$ the area of $\mathrm{EV}$ with a statistical relevance $(\mathrm{p}=0.0000$, Table 3$)$.

The occurrence of LP when swallowing food with liquid consistency was manifested in 6 patients in the subgroup 2, in three patients of subgroup, 3 and in three cases in the control group. In the pasty consistency, PL occurred in 4 patients in the subgroup 2 , in two patients of subgroup 3 and it was absent in the control group. In the solid consistency, LP occurred in 1 patient in the subgroup 1 and it was absent in the control group. Statistical analysis revealed to be significant $(\mathrm{p}=0.0036$ - Proportion Difference Test) in comparison with liquid consistency versus pasty and solid consistencies.

Tracheal aspiration occurred in 5 patients in the subgroup 2 and in 1 patient in the subgroup 3 in the liquid consistency, and it was absent in the control group, without a statistical analysis for casuistic reduction.

The cough reflex when LP occurred was not effective in 5 patients of the subgroup 2 in the liquid consistency, and, four of them in the pasty consistency. In the control 
Table 2. Alimentary stasis found in pasta consistency.

\begin{tabular}{|c|c|c|c|c|c|c|}
\hline \multirow[t]{2}{*}{ Anatomic location } & \multicolumn{2}{|c|}{ Study group } & \multicolumn{2}{|c|}{ Controlgroup } & \multirow{2}{*}{\multicolumn{2}{|c|}{ Total }} \\
\hline & SI & $\mathrm{S} 2$ & S3 & S4 & & \\
\hline LB: & - & - & I & - & - & I \\
\hline LFE & - & - & - & - & I & I \\
\hline PWP & - & - & - & - & 2 & 2 \\
\hline PR & - & । & 2 & - & 3 & 6 \\
\hline EV & - & - & - & - & 3 & 3 \\
\hline$E V+P R$ & । & 4 & । & । & | & 8 \\
\hline $\mathrm{LFE}+\mathrm{EV}$ & - & - & - & - & । & I \\
\hline$L F E+E V+P R$ & - & 3 & - & । & - & 4 \\
\hline$P W P+E V+P R$ & । & - & । & - & - & 2 \\
\hline $\mathrm{LB}+\mathrm{EV}+\mathrm{PR}$ & - & - & - & - & । & I \\
\hline$L B+L F E+E V+P R$ & - & 2 & - & - & - & 2 \\
\hline$P W P+L B+L F E+E V+P R$ & 2 & 6 & 3 & । & - & 12 \\
\hline Total & 4 & 16 & 8 & 3 & 12 & 43 \\
\hline
\end{tabular}

Legend: LB: Lingual basis; LFE: Laryngeal face of the epiglottis; PWP: Posterior wall of the pharynx: PR Piriform recess; EV: Epiglottic vallecula; S1 (stages 1 and 1.5); S2 (stages 2 and 2.5); S3 (stage 3); S4 (stage 4).

Test of proportion differences: $\mathrm{p}=0,0000$.

Table 3. Alimentary stasis found in solid consistency.

\begin{tabular}{lcccccc}
\hline Anatomic location & \multicolumn{2}{c}{ Studygroup } & \multicolumn{2}{c}{ Controlgroup } & \multicolumn{2}{c}{ Total } \\
& SI & S2 & S3 & S4 & & \\
\hline LB: & - & $\mid$ & - & - & - & 1 \\
PR & - & - & - & - & 4 & 4 \\
EV & - & - & - & 1 & 4 & 5 \\
LB + PWP & - & $\mid$ & - & - & - & 1 \\
LB + PR & - & $\mid$ & - & - & - & 1 \\
LB + EV & - & - & $\mid$ & - & - & 1 \\
PR + EV & - & 3 & 2 & $\mid$ & $\mid$ & 7 \\
BL + PR + EV & $\mid$ & $\mid$ & $\mid$ & - & - & 3 \\
LFE + EV + PR & $\mid$ & $\mid$ & - & - & - & 2 \\
$P W P+L B+E V$ & - & - & - & $\mid$ & - & 1 \\
LB + LFE + EV + PR & - & $\mid$ & - & - & - & 1 \\
PWP + LB + LFE + EV + PR & - & $\mid$ & $\mid$ & - & - & 2 \\
\hline Total & 2 & 10 & 5 & 3 & 9 & 29
\end{tabular}

Legend: LB: Lingual basis; LFE: Laryngeal face of the epiglottis; PWP: Posterior wall of the pharynx: PR Piriform recess; EV: Epiglottic vallecula; S1 (stages 1 and 1.5); S2 (stages 2 and 2.5); S3 (stage 3); S4 (stage 4).

Test of proportion differences: $\mathrm{p}=0,0000$.

group, TR was effective in the three cases of laryngeal penetration in the liquid consistency, in statistical significance.

The silent aspiration was observed in five patients in the subgroup 2 and it was absent in the control group with a statistical significance ( $\mathrm{p}=0.0272$ - Fisher test $)$.

\section{DISCUSSION}

The reasons why TR is damaged in PD patients are not clearly explained. It is known that deglutition disorders and ineffective cough reflex contribute to the occurrence of bronchopulmonary infections in parkinsonian patients and they become repetitive as the disease develops $(7,8)$. Deterioration of the deglutition process can often lead to tracheal aspiration and, especially, when the protective mechanics of the airways is defective it can result in complications, suchas malnutrition, dehydration, pulmonary problems, and even death.

Among the complaints mentioned by the patients, sensation of food stuck in throat was significant when comparing both groups, and in their correlation with the 
results of states in $\mathrm{EV}$ and $\mathrm{PR}$ areas, there is an expressive relation between these events, and these anatomic places were mentioned in another study $(11,12)$. In the present research, it was observed that this symptom prevailed in subgroup 2. This data can be associated with the biggest casuistics of this group; conversely, a correlation can be made in the first PD stages -1 to 2.5 - the sensitivity in the laryngotracheal area is preserved, making it possible to have a better perception of the Alimentary residue.

Detecting that without food the cough reflex was found in all of the patients leads to think that cough is a relevant defense mechanism and it works to remover mucus and strange bodies of the upper airways (9), and cough sensitivity is impaired in advanced-stage PD (8). PD's evolving degree and the individual's age reduce the ability of respiratory muscular activity and the expiratory strength, resulting in a weak reflex response or absent $(8,9)$. By finding $84.2 \%$ of reflex responses of non-food cough in an area of vestibular folds in the study group, this study agrees (13) that the receptors of laryngeal cough reflexes are found in the supraglottic membrane. In the control group, stimulating this anatomic area brought 100\% of reflex responses. According to the author (14), although the apparatus touch is a lot more powerful stimulus than saliva or food, if the apparatus touch, especially at the level of vocal folds, does not result in a response, it can be inferred that the stimulus with secretions or food is not converted into effective responses.

The laryngeal sensitivity was reduced in 6 PD patients and in two cases in the control group. In the neurologic diseases, it is common to reduce the laryngeal and TR sensitivity reflex (exposure to sensorial and motor components of the vagum nerve) - (15).

In PD, the difficulty in swallowing food is due to the inability to rapidly and coordinately perform the movements required to swallow. The alterations start by incompletely closing lips and escaping saliva, reducing deglutition reflex, with a likely accrual of saliva in the oral cavity, premature loss of food, stasis in pharyngeal reflexes and laryngeal penetration before deglutition. Chewing can be impaired due to the rigidity of the facial muscles, what makes it difficult to create a combined bolus to be swallowed while reflex is triggered, and then residues are formed in the posterior area of the oral cavity, increasing the possibility of premature escape of food and choking.

The first PD symptoms appear between 40 and 70 years of age and its initial peak is in the sixth decade of life (16). As a whole, motor disorders caused by PD deglutition reveal the disintegration of the automatic and voluntary movements caused by akinesia, bradykinesia and rigidity. Another dysphagia characteristic in the parkinsonian is the fact that it is present even when it does not cause any symptoms, what restraints its early detection (17). In the present study, when swallowing food in liquid and pasty consistencies, it was observed with a higher incidence of stasis in the PR area ( $\mathrm{p}=0.0000$, Tables 1 and 2$)$ and in the solid consistency, stasis prevailed in EV ( $\mathrm{p}=0.0000$, Table 3). This study agrees with the author (18) when describing the significantly higher occurrence of post-deglutition residues in the $\mathrm{EV}$ and $\mathrm{PR}$ areas in $72.5 \%$ in the parkinsonian group of individuals in comparison with the $35 \%$ of the non-parkinsonian group.

The higher incidence of stasis by food in the subgroup 2 can be associated with the first staging, in which the patient develops mechanisms of adaptation to the clinical manifestations that can explain the lowest incidence of stasis in the subsequent stagings.

With respect to the individuals in the control group, $30 \%$ presented some difficulty related to stasis in the pasty consistency and $25 \%$ in the solid consistency. The individuals manifesting alterations are mostly elderly. These findings can be explained by the fact that this populational group usually presents a reduction in the lingual tonus and in that of the phonoarticulatory organs, in association with muscular flaccidity, making it difficult to chew foods that are more solid or consistent, leading the elderly to choose soft foods and more easily swallowed, resulting in swallowing alterations as a consequence of the reduction of the muscular tone and some non-coordination, which is natural in the aging process (11).

An effective deglutition may require wide movements of the tongue, lips, mandible and cheeks, when forming a combined bolus that can be forwarded to pharynx (12). In the parkinsonian patients, the reduction of tongue movements, the reduction in the peristaltic movements and the delay in triggering the deglutition reflex can allow for the stasis in pharyngeal recesses $(19,20)$. The delay in deglutition results in a stasis of the Alimentary bolus in the vallecula space and PR, with the risk of laryngeal penetration and tracheal aspiration, alterations of both pharyngeal motility and the function of the cricopharyngeal muscle (5).

In the evaluation of pharyngeal stage in PD patients (21), 53\% showed: delay in deglutition reflex and longer time to transport food through pharynx. The authors (21) concluded that PD motor disorders have a remarkable influence over oropharyngeal deglutition, and hypokinesia and reduction of spontaneity rate of deglutition are important factors to be considered.

As a result of the muscular rigidity and bradykinesia when making the necessary movements to swallow, and 
the reduced mobility of the oropharyngeal structures, there is an accumulation of food or saliva in pharyngeal recesses, allowing for LP and TA episodes after deglutition. The laryngeal penetration and tracheal aspiration in DP typically occur during and after deglutition (12). In the present study, 57.9\% of PD patients showed LP (42.1\%) and TA (15.8\%), and another study found 40\% TA. Laryngeal penetration and tracheal aspiration can occur when saliva or food penetrates in larynx in three different moments: a) before triggering the deglutition reflex, and, in this case, it is a consequence of the premature escape of food, reduction in the control of tongue movements, absence or delay in triggering the reflex of deglutition; b) during deglutition with inadequate closing of the protective levels of larynx, such as epiglottis cartilage and aryepiglottic folds, vestibular folds and vocal folds; c) after deglutition, when stasis of food occur in the pharyngeal recesses due to the reduction in the anteriorization or elevation of larynx, reduced pharyngeal peristalsis or dysfunction of the cricopharyngeal sphincter (22).

Through the results of deglutition effectiveness, LP and TA, it was possible to correlate efficiency of deglutition with PD staging degree. As the disease evolved, more neurons are degenerated and lose their ability to store dopamine, what contributes to evolve the disease and its complications, such as dyskinesias (2), and increase in the severity of classic PD tetrad.

In PD individuals, the deteriorated rhythm of the pharyngoesophagic mechanism results in abnormalities during Alimentary ingestion, with a subsequent reduction in pharynx peristaltism, an increase in the time forwarding the Alimentary bolus, and it frequently causes symptoms of dysphagia, such as choke and cough $(19,21,23)$. It is important to stress that muscular rigidity is a result of the increase in the muscular resistance and bradykinesia, which in turn is a result of the slowness to perform the movements, they become more accentuated or prevalent as the disease evolves, and, as a consequence, there is a reduction in the laryngeal and pharyngeal mobility for a proper deglutition process and protection of airways. Worse muscular rigidity and bradykinesia can result in pulmonary aspiration (8).

In the present research, LP cases occur in all the food consistencies, with prevalence in the subgroup 2 , followed by the 3 and 1, and tracheal aspiration only in the liquid consistency, being prevalent in subgroup 2 .

Cough reflex was not effective in $13.1 \%$ of patients in the study group, with prevalence in the subgroup 2 and it was effective in the three cases of LP in the control group. This result can be associated with a reduction in the sensitivity of hypoharynx and larynx mucosa. Cough is considered a rapid motor action and when it is weakened in PD it reveals to be ineffective. CR motor component is more implicated in the first PD stages than the sensorial component, and in the advance PD stages, sensorial and motor components are impaired $(7,8)$.

Among the patients who did not show TR effectiveness, one of the subgroup 4 showed stasis for pasty food in all the anatomic places studies (PWP, LB, LFE, EV and PR) and LP. However, the subgroup 4, with more evolution of the disease, has the highest probability and difficulty in the deglutition process and protecting airways.

The concept of silent aspiration is when there is an entrance of saliva, mucus and/or food below the level of vocal folds without a manifestation of cough or another sign of difficulty by the patient (24). In the present study, silent aspiration data were significant $(\mathrm{p}=0.0272)$ when comparing the groups, with a prevalence in the subgroup 2 and it was absent in the control group. Another research (12) found $62 \%$ of laryngeal penetration and $33 \%$ of silent aspiration. $\mathrm{CR}$ absence, restricting the possibility of dysphagia identification, has been associated with a possible sensorial alteration.

PD shows characteristic signs and symptoms, and the deglutition disorder is a direct consequence whose severity follows through the disease evolution. The clinical and instrumental evaluations of deglutition by transnasal fiberoptic laryngoscopy are important to follow up with these patients. This examination has an important advantage in comparison with video fluoroscopy, which is to allow for a structural evaluation of aspects related to the dysfunction of deglutition without needing to offer a contrast or radiation.

RT absence and aspiration configures the final path of a sum of deficits in the mechanisms involved in deglutition, thus increasing the risk of development of bronchopneumonia, with a subsequent increase in the morbidity and mortality of the parkinsonian patient.

\section{CONCLUSION}

From the results of the present study, it can be concluded that:

1. The efficiency of deglutition in the study group has been prevalent in the solid consistency followed by pasta and liquid consistencies. In the control group, deglutition was effective in all the individuals.

2. Cough reflex was efficient in most of the patients in the study group and its inefficiency has been prevalent in the subgroup 2. In the control group, cough reflex was efficient in all of the individuals. 


\section{BiblograpHICAL REFERENCES}

1. Braak H, Tredici KD, Rub U, De Vos RAI, Sterur ENHJ, Braak E. Staging of brain pathology related to sporadic Parkinsons disease. Neurobiology of Aging. 2003, 24:197211.

2. Limongi JCP. Conhecendo melhor a doença de Parkinson: uma abordagem multidisciplinar com orientações práticas para o dia-a-dia. 1ํㅗㄹ ed. São Paulo: Plexus; 2001.

3. Teive HAG. Doença de Parkinson: um guia prático para pacientes e familiares. $2^{\mathrm{a}}$ ed. São Paulo: Lemos; 2002.

4. Meneses MS, Teive HAG. Doença de Parkinson. $1^{\underline{a}}$ ed. Rio de Janeiro: Guanabara Koogan; 2003.

5. Angelis ECde. Deglutição, configuração laríngea e análise clínica e acústica computadorizada da voz de pacientes com doença de Parkinson. [Tese de Doutorado]. São Paulo: Universidade Federal de São Paulo - Escola Paulista de Medicina; 2000.

6. Robbins JA, Logemann JA, Kirshener HS. Swallowing and speech production in Parkinsons disease. Ann Neurol. 1986, 19(3):283-7.

7. Fontana GA, Pantaleo T, Lavorini F, Benvenuti F, Gangemi S. Defective motor control of coughing in Parkinsons disease. Am J Respir Crit Care Med. 1998, 158(2):458-64.

8. Ebihara S, Saito H, Kanda A, Nakajoh M, Takahash H, Arai Het al. Impaired efficacy oh cough in patients with Parkinson disease. Chest. 2003, 124:1009-15.

9. Fontana GA, Lavovorini F, Pistolesi M. Water aerosols and cough. Pulmonary Pharmacology \& Therapeutic. 2002, 15:205-11.

10. Horta W. Escalas clínicas para avaliação de pacientes com doença de Parkinson. Em: Meneses MS, Teive HAG. Doença de Parkinson. $1^{\underline{a}}$ ed. Rio de Janeiro: Guanabara Koogan; 2003, p. 153-62.

11. Bigal A, Harumi D, Luz M, De Luccia G, Bilton T. Disfagia do idoso: estudo videofluoroscópico de idosos com e sem doença de Parkinson. Distúrbio da Comunicação. 2007, 19(2):213-23.

12. Angelis EC de. Doença de Parkinson. Em: Jotz GP, Angelis ECde, Barros APB. Tratado da Deglutição e Disfagia - No adulto e na criança. $1^{\underline{a}}$ ed. Rio de Janeiro: Revinter; 2009, p. $274-8$.
13.Addignton WR, Stephens RE, Widdicombe JG, Rekab K. Effect of stroke location on the laryngeal cough reflex and pneumonia risk. Cough. 2005, 1:01-4.

14. Langmore SE, Schatz K, Olsen N. Fiberoptic endoscopic examination of swallowing safety: a new procedure. Dysphagia. 1988, 2:216-9.

15. Santini CS. Disfagia Neurogênica. Em: Furquim AM, Santini CS. Disfagias Orofaríngeas. $1^{\underline{a}}$ ed. São Paulo: Pró-fono; 1999, p. 19-34.

16. Bertucci Filho DC. Estudo das características clínicas de pacientes com doença de Parkinson de início precoce e depressão[Dissertaçãode Mestrado]. Curitiba: Universidade Federal do Paraná; 2006.

17. Angelis ECde. Voz e deglutição na doença de Parkinson. Em: Andrade LAFde, Barbosa ER, Cardoso F, Teive HAG. Doença de Parkinson - estratégias atuais de tratamento. $2^{\text {a }}$ ed. São Paulo: Seguimento Farma; 2006, p. 197-06.

18. Santoro PP. Avaliação funcional da deglutição por fibronasofaringolaringoscopia na doença de Parkinson: aspectos qualitativos e quantitativos [Tese de Doutorado]. São Paulo: Faculdade de Medicina da Universidade de São Paulo; 2003.

19. Leopold NA, Kagel MC. Pharyngo-esophageal dysphagia in Parkinsons disease. Dysphagia. 1997, 12:11-8.

20. Fuh JL, Lee RC, Wang SJ, Lin CH, Wang PN, Chiang JH et al. Swallowing difficulty in Parkinsons disease. Clin Neurology and Neurosurgery. 1997, 99:106-12.

21. Ertekin C, Tarlaci S, Ayadogdu I, Kiylioglu N, Yuceyar $\mathrm{N}$, Turman AB et al. Electrophysiological evaluation of pharyngeal phase of swallowing in patients with Parkinsons disease. Mov Disord. 2002, 17:942-9.

22. LogemannJA. Aspiration in head and necksurgical patients. Ann Otol Rhinol Laryngol. 1985, 94 (4 Pt 1):373-6.

23. Nagaya $M$, Kachi $T$, Yamada $T$, Igata A. Videofluorographic study of swallowing in Parkinsons disease. Dysphagia. 1998, 13:95-00.

24. Aviv JE, Spitzer J, Cohen M, Ma G, Belafsky P, Close LG. Laryngeal adductor reflex and pharyngeal squeeze as predictors of laryngeal penetration and aspiration. Laryngoscope. 2002, 2:338-41. 